\title{
Types of Barriers to the Integration of the EU Gas Market
}

\section{Mariusz Ruszel}

Department of Economics Faculty of Management Rzeszow University of Technology

Powstancow Warszawy 8, 35-321 Rzeszow, Poland

$\Gamma$ Crossef $h t t p: / / d x . d o i . o r g / 10.5755 / j 01 . e i s .0 .9 .12803$

\section{EIS 9/2015}

Types of Barriers to the Integration of the EU Gas Market

Submitted 04/2015

Accepted for publication $07 / 2015$

\section{Abstract}

The article discusses the problem of barriers to the integration of the EU internal energy market. The study is concentrated on gas market. The EU needs to combine particular gas markets and integrate gas networks in order to create energy highways.

This article applies a combination of factor and systematic analysis and comparative research methods. The study includes the analysis of official EU documents such as documents and directives, as well as the Network Code on Capacity Allocations.

The analyses and research tasks include: the analysis of the potential model of integration of the gas market, the analysis of the level of reserved capacity of existing interconnectors in Europe by 2030 , the analysis of the role of LNG terminals on the EU gas market, the analysis of traffic capacity of the existing interconnectors that allows to determine further investments and the types of barriers to the gas market integration process.

The results of the article are: the direction of the integration process of the EU gas market, identification of the significance of LNG terminals in the gas market in Europe, identification of the main types of barriers which could protect the national gas markets and contribute to slowing down the integration process. The integration of the EU gas market is a challenge because the member states will protect their interests as well as their own energy companies. The creation of the EU internal energy market necessitates the development of energy infrastructure as well as good regulations. It is also important to increase the understanding of and trust in the energy field between European Union countries, at the expense of national interests, in order to achieve energy solidarity in the EU gas market.

KEYWORDS: gas market, energy market, interconnector, gas pipeline, LNG terminal.

In the European Union (EU) there are principal market freedoms such as the free movement of goods, services, capital and labour. These fundamental principles are the basis of the concept of internal energy market, which should maintain flexible exchange of electricity and gas between member states (Dohms, 1994). For this reason, the EU needs to develop energy infrastructure (electricity and gas networks such interconnectors and underground gas storages) as well as energy regulations. Since the liberalisation process that started in the 1990's, the European electricity market has progressively been integrating (Creating Europe, 2015). The same process has slowly developed on the gas market because the structure of the gas market is based on monopolistic energy companies which protect their own interests and share in the market (Ruszel, 2014b). For this reason, the process of integration of EU gas market is a big challenge for Europe. On the one hand, the EU would create an integrated gas market, but on the other hand, EU coun-

\section{Introduction}

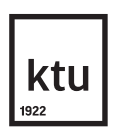

European Integration Studies No. 9 / 2015 pp. $155-160$

DOI 10.5755/j01.eis.0.9.12803 (c) Kaunas University of Technology 
tries would protect their national markets. Therefore, the EU should assist the development of gas infrastructure, market competition and harmonization of regulations.

The main research problem of this paper is to identify the barriers to integration of the EU gas market. For this reason, the aim of this article is to answer the study questions such as: how the gas market will be integrated, what will be the role of LNG terminals, and what kind of barriers will slow down the process of gas market integration in Europe. Therefore, the tasks of this paper are to analyze the potential form of the EU gas market model integration, the level of reserved capacity of gas interconnectors, the role of LNG terminals in the EU gas market and the barriers to the gas market integration process in Europe. Factor analysis is applied in this article in order to identify the most important barriers to gas market integration and to assess the EU gas infrastructure. The comparative method is used to collate the capacity of gas interconnectors in different parts of Europe. Also, the political analysis method and the forecasting technique are applied to obtain, not only theoretical, but also practical input.

The main results of this article are: identification of the important direction of EU gas market integration, the determination of the role of LNG terminals in the European gas market, and identification of the main types of barriers to the integration process of the EU gas market.

The model of integration of the EU gas market
The existing gas networks were built following the model which takes into account the costs of natural gas transportation. In accordance with long term gas contracts between exporters and importers, transit pipelines were constructed. The energy infrastructure should be used effectively and provide the minimizing of the gas supplies cost (Lochner, 2011), especially in the time of global market competition. Sergio Ascari stressed that North America is the only really competitive gas market in the world (Ascari, 2011). The American model is based on the unbundling of transportation and supply, regulated tariffs, investments and transparency decisions (Ascari, 2011). Europe should draw conclusions from the American integration process and adopt it in the European model. Nowadays, the European Union faces energy challenges connected with the energy market, such as the harmonisation of tariffs regulation, the assertion of profitability of interconnectors, the regulation of capacity networks (Network Codes) and the balance of the national intervention in the gas market. Of particular importance is good Network Codes regulation, which can enhance open access to transmission systems in order to increase the flexibility of gas flows through Europe. With these principles in mind, Boaz Moselle and Martin White underline that the level of intervention in the energy market should be low and the EU should take the necessary countermeasures to reduce congestions in gas interconnectors (Moselle, White, 2011).

In the models of energy integration it is emphasized that a conjunction of neighbouring gas markets helps to create small integrated gas markets. Jean-Michel Glachant claims that the creation of regional gas markets is first step to the internal gas market in the EU (Glachant, 2011). Integrated gas networks will be connected with centres of gas distribution (gas hubs) in Europe, which is illustrated by Beatrice Petrovich (Petrovich, 2013). This solution supports energy security and increases the position of member states in the situation of gas crisis. After gas crises of 2006 and 2009 , the EU is in the better position to understand this type of risk of security of gas supplies. Previously, gas crises were the catalyst in the integration process on the gas market in Europe. The target model of gas market integration should posit the diversification not only of the direction but also of sources of gas supplies. On that account, LNG terminals as "entry points" to the European gas networks play an important role in strengthening energy security. Anne Neumann sees the relevance of LNG terminals in the energy market (Neumann A., 2008). In the theoretical approach, researchers from IFEE stressed that it is important to guarantee the pressure in the pipelines for security and operational reasons, and that is why it is so crucial to use balancing systems and 
flexibility tools (Dickx, Miriello, Polo, 2014). Furthermore, the theoretical framework developed by Roberto Roson and Franz Hubert gives some analyses concerning bargaining on the network markets (Roson, Hubert, 2014). To conclude, Europe needs to develop the target model of gas integration to strengthen energy security as well as competitiveness of the European industry. The EU should find a compromise between national interests in the energy sector and the European interest to develop the draft of the European Energy Union (Energy Union, 2015).

An LNG (liquefied natural gas) terminal is a strategic energy infrastructure which is a part of the critical infrastructure (Yusta, Correa, Lucal-Arantegui, 2011). Therefore, this energy infrastructure should be protected from different types of risks and threats. LNG terminals have a significant role because they allow to diversify the directions and sources of gas supply (Geist, 1983; Sakmar, Kendall, 2009). Moreover, LNG terminals could strengthen the competitiveness on the gas market (Dorigoni, Graziano, Pontoni, 2010). Thereby, this energy infrastructure supports energy security and is a significant instrument in a process of negotiation with others gas exporters who supply the natural gas by pipelines. The International Energy Agency (IEA) has worked out the Model of Short Term Energy Security (MOSES), in which it is stressed that LNG terminals are the "entrance" points to the EU gas market and they strengthen the security of supply as well as energy security (Jewell, 2010). In comparison with pipelines, LNG terminals support the flexibility of natural gas supply. Regardless of this fact, it is verified that the more LNG terminals the state has, the less it wishes the development of interconnectors with other countries. This is confirmed by the policy of Spain or Italy, which have a lot of LNG terminals but do not have good gas connections with neighboring countries. Nowadays, the EU countries use the capacity of LNG terminals in $25-30 \%$ but the situation could change if a conflict or gas crisis occurs in the regions such as North Africa or Russia. Norway is still the most stable natural gas exporter. To conclude, LNG terminals strengthen the security of gas supply but on the other hand they could reduce the political will to develop the capacity of gas interconnectors in Europe (e.g. Spain, Italy).

Firstly, the main type of barrier to integration of the gas market is the political barrier. A clear conception of internal gas market requires political acceptance among the governments of the EU countries and the EU leaders. Not all member states are able to compete on the market and for this reason they will use this instrument to protect their markets. Moreover, European countries have different gas contracts with exporters: some states pay more for natural gas and other pay less for the same gas from the same supplier. This means that on the internal gas market with flexible gas exchange the countries which pay less and have well-developed energy infrastructure (e.g. Germany) will have an advantage over other European countries. It is a really dangerous situation for Europe, because some countries' energy policy with the main exporter is aimed at the protection of the low price for natural gas. It can be seen in Hungary, where the discount on Russian gas is more important than the common interest of the EU. The situation is similar in Germany, where the business lobby would protect the relation with Russian companies - also in the energy sector - regardless of the political situation in Europe. To conclude, the European Union countries have different interests and protect their own interests instead of developing the solidarity and European Energy Union.

Secondly, it is the lack of harmonization of the standards and rules that impedes the gas trade. Although the EU has adopted directives and regulations and has taken action to develop the liberalization of gas market, the prices of gas in some countries are regulated. Therefore, it is crucial to deregulate the gas price on the national markets and strengthen the competition on the EU gas market. It is also important to map out and implement the Network Code on Capacity Allocations. "Network Codes are specific tools for implementation of a single energy market in

\section{LNG terminals - integration or fragmentation gas market}


the EU. They include common rules for functioning and managing energy systems and are aimed at eliminating technical barriers for further market integration" (Framework Guidelines, 2014). These rules could determine the device of the gas market operation.

Thirdly, the EU countries do not have enough gas infrastructure to exchange natural gas flexibly. Between some EU countries there is no gas infrastructure (e.g. France - Italy, Poland - Lithuania, Slovakia - Hungary) and some states are separated from the rest (e.g. the Baltic states: Lithuania, Latvia and Estonia). For this reason, the EU has adopted the Regulation of the European Parliament and the EU Council no. 347/2013 of 17th April 2013 on the guidelines regarding the transeuropean energy infrastructure to support the development of energy infrastructure (Regulation, 2013). Moreover, European Union countries do not have sufficient capacity of gas interconnectors to send natural gas between member states flexibly and in many places there are so called "bottlenecks" (Ruszel, 2014a). For this reason, it is necessary to develop the existing gas interconnectors to ensure their proper capacity and bidirectional usage (Dieckhöner, Lochner, Lindenberger, 2013). Regardless of this fact, EU countries should invest in national gas grids to strengthen their capacity, because these gas pipelines will be part of European gas networks (Hall, Dart, 2014). The big challenge for the countries and gas operators is how to finance the investment; therefore they should apply for EU funds. In 2013, the European Commission announced the list of 248 projects of common interest (Communication, 2013).

Fourthly, there are the gas contracts in Europe based on long-term rules and different clauses such as take or pay. It means that this type of gas contract has significant impact on the capacity of pipelines and gas interconnectors. Moreover, the states have taken decisions about the choice of the sources of natural gas supply to take into consideration the cost of the transport. For this reason, member states have decided to choose the closest gas suppliers to reduce the costs and risks connected with supply. Therefore, Spain or Portugal do not import natural gas from Russia, and Lithuania from Algeria or Morocco. The majority of EU countries have signed long-term gas contracts until 2025 or even 2035. Moreover, the capacity of interconnectors between EU states is also contracted in some places in 100\%, but used only up to 50-60\% (ACER, 2013). The capacities of interconnectors of, among others, Czech-Germany (Waidhaus) or Spain-Portugal (Badajoz point) have been contracted till 2035 and Slovakia-Austria (Baumgarten) or Netherlands-Germany (Bocholtz) have been already contracted till 2030 (Ruszel M., 2014a). It means that the gas companies have bought the capacity in the interconnectors in order to protect the national gas market. In that way they could buy the capacity but not use it, and hence block the import. If this operation continues in the future and the Network Codes do not terminate these actions, then the development of competition in the gas market will be slower.

Conclusions

The European Union needs to build new gas interconnectors as well as develop the capacity of the existing ones. The architecture of gas pipelines was built according to the model that takes into account the cost of transportation as well as long-term contracts. For this reason, the gas infrastructure should support the minimizing of both the risks of gas supply and the costs of transportation. In the time of gas market integration, EU countries will look for the competitive advantage, which should be the lower price for importing natural gas. Therefore, the cost of transportation will still be one of the main factors to chose the gas supplier and influence the shape of the EU gas market model. The integration of gas market contributes to the creation of regional markets, which will be connected with gas hubs. First of all, it is crucial that Europe needs to develop the EU gas market model to strengthen not only the security of supply but also the competitiveness of European industries.

LNG terminals will have an important role on the gas market, because they could diversify the natural gas suppliers and increase the number of "entrance" points to the market. Regardless of 
this fact, the EU countries which have this energy infrastructure has less developed interconnectors with neighbor states. Therefore, the states with well-developed LNG terminals could slow down the integration process on the EU gas market. On the other hand, a geopolitical conflict or gas crisis causes LNG terminals to play a significant role in supporting the security of gas supply. To conclude, the role of this installation could change if some risks will come true. What has a significant impact on the competitiveness of liquefied natural gas is both the price of this gas and transportation. Then the usage of LNG terminals should be changed when there will be a gas crisis or problem with gas supply through transit pipelines.

The main types of barriers in the integration process of the EU gas market are the political will, the lack of harmonization of the common rule and regulation (network codes), the lack of sufficient gas infrastructure in Europe and long-term gas contracts. For this reason, EU countries need to develop gas infrastructure that would enable the free exchange of natural gas between them. Moreover, EU countries need the transition in the long-term gas contracts because they need more competition on the gas market. Therefore, it is important to strengthen spot transaction and the trade of gas in the stock markets in Europe. Certainly, the long-term gas contracts will still exist but the proportion between long-term contracts and short contracts (spot transition) should be changed (Zajdler, 2012). Because a lot of capacity in gas interconnectors have been already contracted, Europe needs a networks code which would influence the pace of integration of the gas market. EU institutions such as the Agency for the Cooperation of Energy Regulators (ACER) and European Network of Transmission System Operators for Gas (ENTSO-G) have a significant role in this aspect, as they support the process of integration of the EU gas market by contributing to the regional integration of gas markets as well as the approval of network codes (Ruszel, 2014b). Of particular importance is good network codes regulation, which can enhance open access to transmission systems in order to increase the flexibility of the gas flows thought Europe. Moreover, the EU should find a compromise between national interests in the energy sector and the European interest to develop the draft of the European Energy Union. The EU needs a more solidarity to face the gas market integration challenges such as: the harmonization of tariffs regulation, the assertion of profitability of interconnectors, the regulation of capacity networks (network codes) and the balance between national interventions in the gas market. Member states and their energy companies will always think about their national interests and this will never change, as well as the increasing competition between countries, regions and companies. Regardless of this fact, Europe needs more responsibility and common action to develop gas infrastructure which could be used even if a gas crisis arises. Without common thinking and cooperation between EU countries, Europe will be weak. Therefore, the EU needs to "speak with one voice" to support the energy security and competitiveness of the economy.

ACER/CEER Annual Report on the Results of Monitoring the Internal Electricity and Natural Gas Markets in 2012 (2013). Agency for the Cooperation of Energy Regulators.

Ascari S. (2011). An American Model for the EU Gas Market? EUI Working Paper RSCAS 2011/39. Robert Schuman Centre for Advanced Studies. Florence School of Regulation.

Dickx L., Miriello C., Polo M. (2014). Balancing Systems and Flexibility Tools in European Gas Markets. Research Report n. 14. Centre for Research on Energy and Environmental Economics and Policy at Bocconi University.
Communication from the Commission to the European Parliament, the Council, the European Economic and Social Committee and the Committee of the Regions (2013). Long term infrastructure vision for Europe and beyond, European Commission, $\operatorname{COM(2013)~} 711$ final, Brussels 14.10.2013.

Creating Europe's Internal Market for Electricity. Retrieved February 16, 2015, from http://networkcodes.entsoe.eu/what-are-network-codes/creating-europes-internal-market-for-electricity

Dieckhöner C., Lochner S., Lindenberger D. (2013). European natural gas infrastructure: The impact of market developments on gas flows and physical market

\section{References}


integration. Applied Energy, 102, February, 994-1003. http://dx.doi.org/10.1016/j.apenergy.2012.06.021

Dohms R. (1994). The development of a competitive internal energy market in the European Community. Connecticut Journal of International Law, 9.

Dorigoni S., Graziano C., Pontoni F. (2010). Can LNG increase competitiveness in the natural gas market. Energy Policy, 38, 7653-7664. http://dx.doi. org/10.1016/j.enpol.2010.08.004

Framework Guidelines and Network Codes (2014). Retrieved February 10, 2014, from http://www. ure.gov.pl/en/international-cooperat/third-energy-package/170,Framework-Guidelines-and-Network-Codes.html

Geist J.M. (1983). The role of LNG in energy supply. International Journal of Refrigeration, 6 (5-6), September-November, 283-297. http://dx.doi. org/10.1016/0140-7007(83)90008-7

Glachant J.-M., (2011). A vision for the EU gas target model: The MECO-S model. EUI Working Paper, RSCAS 38.

HallS., Dart J. (2014). One in three EU gas interconnectors contractually congested: ACER. Retrieved July 8, 2014, from http://www.platts.com/latest-news/ natural-gas/brussels/one-in-three-eu-gas-interconnectors-contractually-267452001

Jewell J. (2011). The IEA Model of Short-term Energy Security (MOSES). Primary Energy Sources and Secondary Fuels. International Energy Agency. http://dx.doi.org/10.1787/5k9h0wd2ghlv-en

Lochner S. (2011). Identification of congestion and valuation of transport infrastructures in the European natural gas market. Energy, 36 (5), 2483-2492. http://dx.doi.org/10.1016/j.energy.2011.01.040

Moselle B., White M. (2011). Market design for natural gas: the Target Model for the Internal Market, LECG Report for the Office of Gas and Electricity Markets, London.

Neumann A. (2008). Linking Natural Gas Markets - Is LNG Doing Its Job? Discussion Paper 822, 2-3. Deutsches Institut fuer Wirtschaftsforschung, Berlin.

Petrovich B. (2013). European gas hubs: how strong is price correlation?, NG 79, The Oxford Institute for Energy Studies.
Regulation (EU) No 347/2013 of the European Parliament and of the Council of 17 April 2013 on guidelines for trans-European energy infrastructure and repealing Decision No 1364/2006/EC and amending Regulations (EC) No 713/2009, (EC) No $714 / 2009$ and (EC) No 715/2009, Official Journal of the European Union L 115/39.

Roson R., Hubert F. (2014). Bargaining Power and Value Sharing in Distribution Networks: A Cooperative Game Theory Approach. Centre for Research on Energy and Environmental Economics and Policy at Bocconi University. http://dx.doi.org/10.2139/ ssrn.2386717

Ruszel M. (2014a). Assessment of the gas infrastructure in the context of establishing internal energy market. International Multidisciplinary Scientific Conferences on Social Sciences \& Arts. SGEM Conference on Political Sciences, Law, Finance, Economics \& Tourism, 3-9 September 2014, Bulgaria (ISSN: 2367-5659). Conference Proceedings, Volume 1, Albena 2014, 21-27.

Ruszel M. (2014b). Challenges and opportunities of the common EU energy market. In S. Konopacki (Ed.), Europe in the time of crisis (pp. 159-168). Łódź University Press, Łódź-Kraków.

Sakmar S., Kendall D. (2009). The Globalization of LNG Markets: Historical Context, Current Trends and Prospects for the Future. Proceedings of the 1st Annual Gas Processing Symposium, 32-43.

Yusta J. M., Correa G. J., Lucal-Arantegui R. (2011). Methodologies and applications for critical infrastructure protection: State-of-the-art. Energy Policy, 39, 6100-6119. http://dx.doi.org/10.1016/j.enpol.2011.07.010

Energy Union Package (2015). Communication from the Commission to the European Parliament, the Council, the European Economic and Social Committee, the Committee of the Regions and the European Investment Bank. A Framework Strategy for a Resilient Energy Union with a Forward-Looking Climate Change Policy. European Commission, Brussels, 25.2.2015, COM(2015) 80 final.

Zajdler R. (2012). The future of gas pricing in long-term contracts in the Central Eastern Europe. Global market trends versus regional particularities. Warsaw.

\section{About the MARIUSZ RUSZEL author PhD, Assistant Professor}

Department of Economics Faculty of Management Rzeszow University of Technology

\section{Address}

Powstancow Warszawy 8, 35-321 Rzeszow, Poland

Tel. +48178651403

E-mail: mruszel@prz.edu.pl 